\title{
Health Care and Patient Safety: The Failure of Traditional Approaches - How Human Factors and Ergonomics Can and MUST Help
}

\author{
James P. Bagian \\ Center for Healthcare Engineering and Patient Safety, University of Michigan, Ann Arbor, Michigan
}

\begin{abstract}
Hazard and harm to patients as well as inefficiencies associated with health care have been well described as worldwide problems that result in hundreds of thousands of patient deaths and billions of dollars of waste every year. The underlying causes for these problems have not been nearly so well described; more importantly, generalizable mitigation strategies have not been effectively identified or used. The current state of health care and patient safety will be discussed with particular attention to the essential role that an engineering-based approach, which is heavily rooted in human factors and ergonomics, must play if real and sustainable progress in the safe and efficient delivery of health care is to be achieved. Specific case studies that illustrate the compelling opportunities for the application of human factors and ergonomics-related knowledge will be discussed. ๑ 2011 Wiley Periodicals, Inc.
\end{abstract}

Hazard and harm to patients that results from treatment by their health-care system and providers is a fact. This problem is world-wide, with a resulting magnitude of harm reported to be in the hundreds of thousands of patient deaths per year and billions of dollars of waste (Baker, et al., 2004; Commonwealth Department of Health and Family Services, 1996; Kohn, Corrigan, \& Donaldson, 2000; Mogensen, Poulsen, \& Wendelboe, 2002). Discussion and literature dealing with harm to patients goes back many decades (Bates et al., 1995; Brennan et al, 1991; Schimmel, 1964/2003; Steel et al., 1981/2004). Al-

This was the Keynote Address at the 3rd International Conference on Applied Human Factors and Ergonomics, July 17-20, 2010, Miami, Florida.

Correspondence to: James Bagian, University of Michigan, 2753 IOE Building, 1205 Beal Avenue, Ann Arbor, MI., 48109-2117. Phone: 734 930-5890; e-mail:

JBagian@umich.edu

Received: 20 September 2010; accepted 20 September 2010 View this article online at wileyonlinelibrary.com/journal/hfm DOI: $10.1002 / \mathrm{hfm} .20261$ though there are ample examples in the literature describing the undesirable outcomes that have occurred, the health-care field has not been successful in devising and implementing strategies, tools, and techniques that have been successfully and sustainably used on a widespread basis. This lack of generalizable success may stem from a continuing failure to identify the underlying systems-based causes for these problems. In many cases the search for causation ends with superficial descriptions that are anything but systems based and only identify human errors but do not examine the underlying causes for the human errors. This response of treating the symptoms instead of the underlying causes is not the exclusive challenge of health care but rather a characteristic demonstrated in many circumstances when organizations are confronted with mishaps resulting in catastrophic loss of life or property.

In the health-care industry there has been a traditional emphasis on the individual autonomy of healthcare providers. Practitioner autonomy certainly is appropriate to a certain extent because the diagnosis and treatment of a patient needs to be responsive to the specific needs of that patient. Individual autonomy can 
readily become counterproductive when it results in practitioner and organizational behavior that is more rooted in personal preferences, convenience, and tradition rather than being evidence based. Examples of unwarranted variation in health care are commonplace (Bates 2007). For example, a common practice to treat diabetic patients while they are receiving care in the hospital is a technique called sliding scale insulin coverage. This technique relies on the measurement of the patient's blood glucose level at periodic intervals and then having the nurse administer insulin in varying amounts depending on the measured level of the blood glucose. Using procedures where the nurse acts as one of the elements in the closed feedback loop to treat the patient is certainly not an inappropriate technique. A complicating factor arises, however, when the nurse is caring for more than one diabetic patient on sliding scale orders and each patient is under the care of a different physician. In these situations it is entirely possible that each patient has a different treating physician who prescribed a different insulin dosage for the same measured blood glucose level. Although it is quite possible that each physician's prescribed dosage is medically correct from a technical perspective, such variation makes it increasingly likely that an individual nurse may inadvertently give a particular patient a dose of insulin that was not intended. Unfortunately, there is often little, if any, active involvement of the physicians, nurses, or hospital management to eliminate or reduce this type of variation, which often offers the patient no increased technical benefit but subjects the patient to unnecessary risk. More importantly, this failure to take action is more often than not due to failure to detect or recognize that unnecessary variation is a risk that can and should be addressed. Similar examples extend to the area of medical practice and technique. It is quite common to see substantial differences in the way care is technically provided from one floor to another in the same hospital as well as between one shift and the next shift on the same nursing unit. Similarly, the clinical approaches and techniques used by physicians can vary dramatically among hospitals as well as among physicians at an individual hospital and often represent what they were taught in training, is their particular individual preference, or is the custom at their particular location. This variation is often the result of health-care practitioners being ignorant of the additional risk to which they are subjecting their patients rather than the result of an explicit and intentional choice that was made based on a careful consideration of available evidence. Such ignorance of the advantages that accrue from standardized work are to be expected

\section{JCAHO 2003 National Patient Safety Goal's "Boxscore"}

\begin{tabular}{|l|l|l|c|c|c|}
\hline NPSG \# & \multicolumn{1}{|c|}{ Statement of Goal } & \multicolumn{1}{|c|}{$\begin{array}{c}\text { Engineering vs } \\
\text { Personal (Behavior or } \\
\text { Practice Changes) }\end{array}$} & Schedule & $\begin{array}{c}\text { Random } \\
\text {-Unannounc } \\
\text { ed" }\end{array}$ & $\begin{array}{c}\text { Difference } \\
(+/-)\end{array}$ \\
\hline 1a & Two identifiers & Personal Changes & 96.2 & 85.4 & 11 \\
\hline 1b & Timeout before surgery & Personal Changes & 91.1 & 77.1 & 14 \\
\hline 2a & Read back & Both & 92.6 & 89.6 & 3 \\
\hline 2b & Standard abbreviations & Both & 76.5 & 64.6 & 12 \\
\hline 3a & $\begin{array}{l}\text { Remove concertrated } \\
\text { electrolytes }\end{array}$ & Engineering Change & 97 & 95.8 & 1 \\
\hline 3b & $\begin{array}{l}\text { Standardize drug } \\
\text { concentrations }\end{array}$ & Engineering Change & 99.4 & 100 & -1 \\
\hline 4a & Use preop checklist & Both & 98.5 & 93.7 & 5 \\
\hline 4b & Mark site & Personal Changes & 93.8 & 68.7 & 25 \\
\hline 5a & No free-flow IV pumps & Engineering Change & 98.6 & 100 & 0 \\
\hline 6a & Maintain alarms & Engineering Change & 97.9 & 97.9 & -1 \\
\hline 6b & Audible alarms & 94.7 & 88.4 & 0 \\
\hline
\end{tabular}

Figure 1 Joint Commission on Accreditation of Healthcare Organizations (JCAHO) 2003 National Patient Safety Goals Boxscore. 
because formal training in these and other concepts dealing with systems-based problem recognition and solutions that take into account those factors affecting systems and individual performance are not typically available or recommended for health-care providers during their training.

Technology, its use in the care of patients, and the vulnerabilities and hazards that it introduces are other areas that can have a catastrophic impact on patients. In addition to the more straightforward issues, such as software "bugs" and inadequate mechanical design, an especially troublesome issue related to the design of equipment so that it can be effectively and efficiently used by practitioners. Displays and controls of medical devices and the documentation that accompanies them often appear devoid of any human factors or ergonomics (HFE) influence. Design inadequacies are often not discovered until after a device has been released for sale. The application of formal effective usability testing is the exception rather than the rule. (Anderson et al., 2010 [Submitted for publ in this issue]). Inadequacies that are discovered once the device is in use are frequently addressed through documentation-based interventions that essentially instruct the users to "be careful," not a terribly robust or effective countermeasure. For example, pumps have existed that intravenously deliver medication to patients and have a user interface flawed to the extent that nurses could unknowingly give doses that were ten times higher than intended. When approached, the manufacturer's initial response was, in essence, "If the nurses would just perform the task correctly there wouldn't be a problem." Unfortunately, the design was such that the nurse was not supplied with a clear indication that the dose that the pump was delivering was not what she or he had intended. Had effective testing and evaluation been done prior to the marketing of the pump, this vulnerability could have been detected and fixed prior to any patient being injured. Other examples of design shortcomings exist in devices such as are used in surgical and other procedures. For instance, fiberoptic endoscopes that are used to examine a variety of body cavities have come under close scrutiny in recent years because of difficulty in assuring that they are properly cleaned after being used on one patient and prior to being used on a subsequent patient (Jolly et al., [submitted for publ in this issue]; VA National Center for Patient Safety Alerts, 2010). On its surface, this task would appear to be trivial; however, once the complex set of tubing and other devices that are involved are taken into consideration together with the associated intricate and different procedures required for each component, it is no wonder that frequent problems regarding cleaning, disinfection, and sterility arise. In this case, testing and analysis of not only the operation of the scope during the medical procedure but also during the cleaning process would have been of value. Usability testing informed by a knowledge of HFE would have been of tremendous value.

Other evidence of the need for a systems-based approach that is heavily informed by a knowledge of HFE can be seen in policy decisions where the VA National Center for Patient Safety examined the effectiveness of the Joint Commissions (TJC) National Patient Safety Goals (NPSGs) (Figure 1) based on TJC data (The Joint Commission, 2003). In comparing scheduled and unannounced surveys to assess compliance of healthcare institutions on achieving the goals of the NPSGs some interesting patterns were noticed. The compliance of those goals that were more strongly rooted in engineering-type solutions, the success of which was not dependent on day-to-day vigilance and the personal performance of individuals, showed little difference in performance as compared to those that were highly dependent on continued individual vigilance and personal performance (Figure 2). This variation in impact, or strength of action, was not anticipated by TJC but if more HFE-type knowledge had been incorporated during the formulation of the NPSGs a greater likelihood of success might have been achieved.

Design of the physical plant is another area that can benefit from HFE input. Examples include patient falls that result in serious injury. Falls are a problem for virtually all health-care facilities. Issues such as lighting and reliable visual reference, balance, cognitive capability, and communication of information are all contributors to fall injury. Appropriate design informed by HFE expertise could contribute to the mitigation of fall injury risk. Safety in magnetic resonance imaging (MRI) areas is another area in which HFE-informed design could be put to good use. Strong magnetic fields are present in MRI facilities, and there have been numerous cases in which ferromagnetic objects have inadvertently been brought into the imaging areas resulting in fatal injuries and substantial damage (Figure 3). Designs that address the various contributing factors can reduce the likelihood of these events.

Individually based human performance issues also contribute to events that harm patients. Factors such as fatigue continue to present issues that negatively 


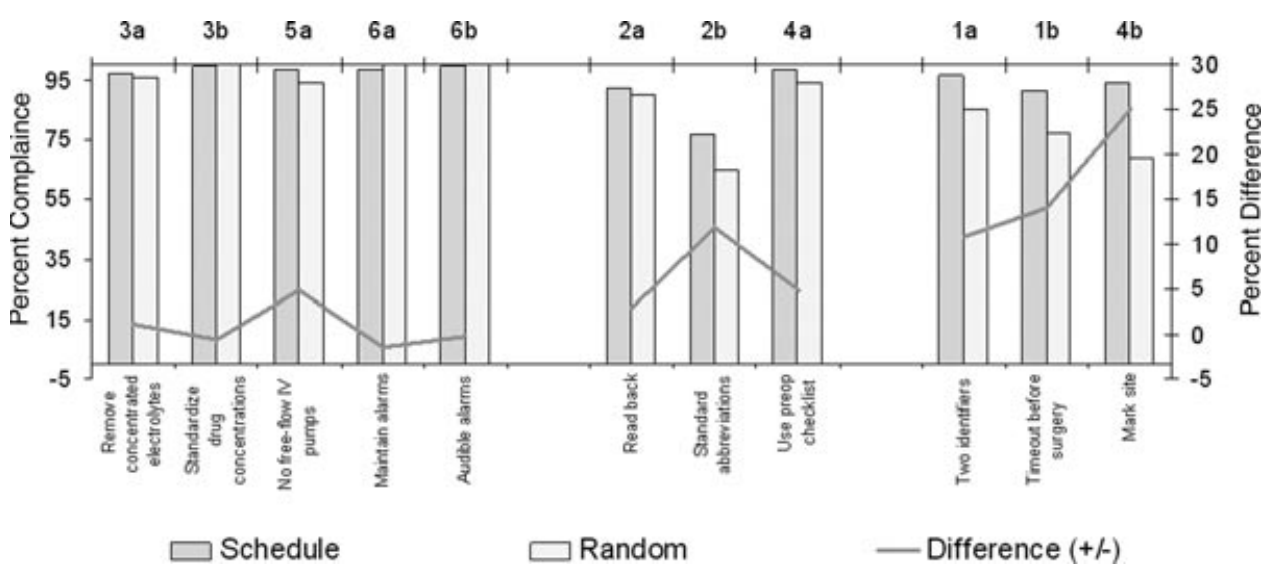

Figure 2 Percentage difference $( \pm)$ : Engineering only, engineering/behavior, behavior only.

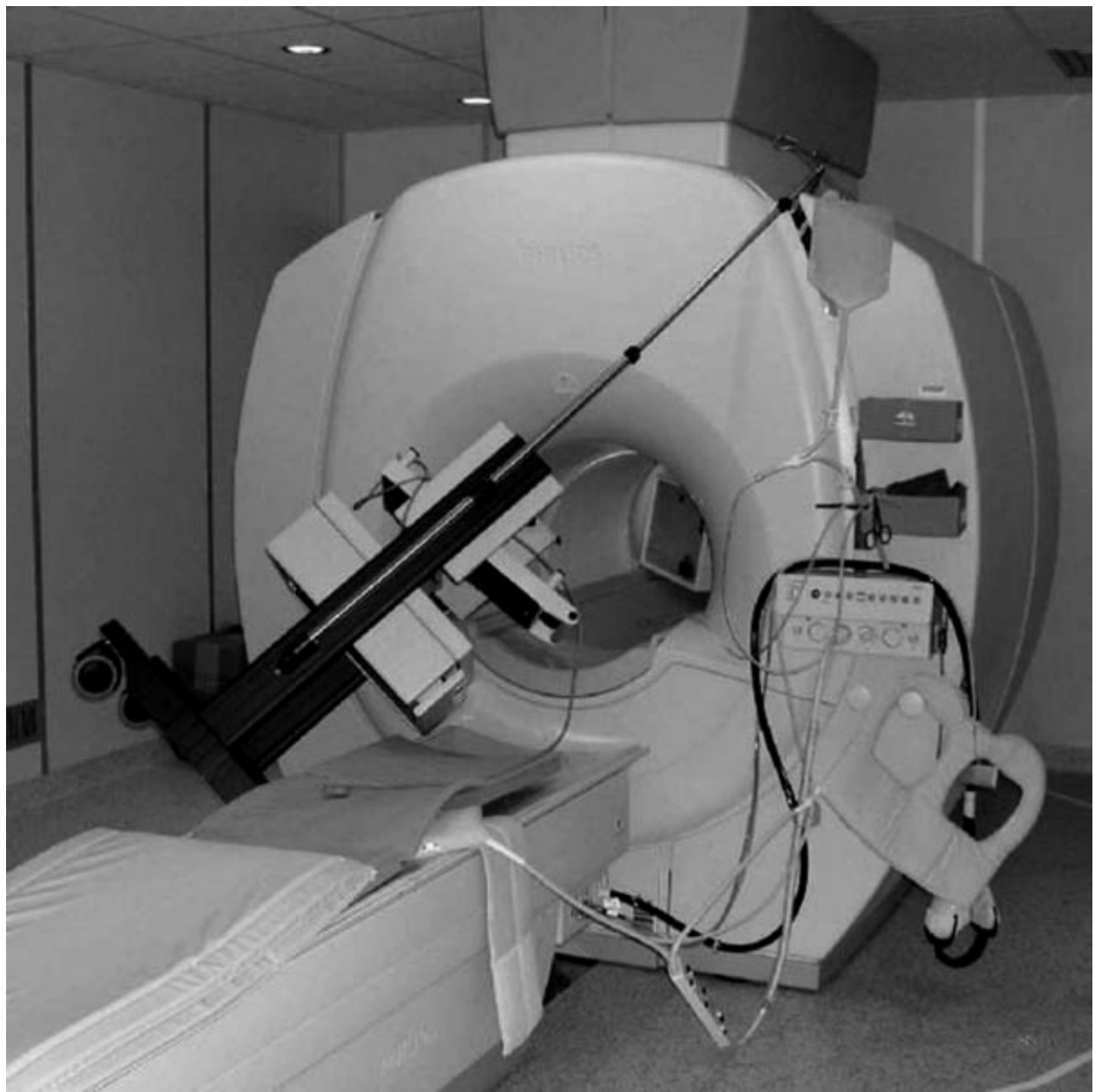

Figure 3 Magnetic resonance imaging. Photo courtesy of www.simplyphysics.com. 
impact patient care. Although fatigue and its impact have begun to be addressed with regard to physician training programs, there has been little or no activity to address the practices of health-care providers after they have completed their training programs. Interventions that go beyond the overly simplistic interventions of work hour regulation are needed and should include interventions that address both education and fatigue management strategies and techniques. Inadequate communication is cited as being the single largest cause of patient safety-related events (Lingard et al., 2004; Sutcliffe, Lewton, \& Rosenthal, 2004; The Joint Commission's Annual Report, 2007). This communication involves not just written communications but especially verbal communication among various health-care professionals, especially in situations where authority gradients play a role. Because health care is a hierarchical field, it is not surprising that communication has been identified as a primary problem. Interventions such as Medical Team Training have begun to be applied primarily in the operating rooms and intensive care units, but its use is far from widespread (Neily et al., 2010).

There are many areas in which the application of HFE knowledge can positively impact the delivery of health care from not only a safety perspective but also from an effectiveness and efficiency standpoint. The opportunities run the gamut from equipment and physical plant design to process issues that address organizational as well as personal factors. In some cases re-engineering of existing facilities, equipment, and processes is what is required. In others, new tools and approaches are needed (Bakdash \& Drews [submitted for publ in this issue]; Drews et al. [submitted for publ in this issue]; Bradley [submitted for publ in this issue]; Williams [submitted for publ in this issue]; Lesselroth et al., [submitted for publ in this issue]). There is not a general understanding by the health-care community that HFE-related issues represent some of the fundamental causes of the problems that are currently encountered. There is also little knowledge of the capabilities that HFE professionals possess. It is imperative that the HFE community take the initiative to become involved in the solution to these health care-related problems. Health care-related problems amenable to HFE-based solutions are present on a global basis, and there is a growing appreciation that these problems need to be dealt with. Venues where HFE can have an impact range from device and software manufacturers and ven- dors, to regulatory bodies, to health-care delivery organizations such as hospitals and hospital systems. This is an opportunity for the HFE community to make a significant contribution. IT MUST ACT NOW.

\section{References}

Baker, G. R., Norton, P. G., Flintoft, V., Blais, R., Brown, A., Cox, J., et al. (2004). The Canadian adverse events study: the incidence of adverse events among hospital patients in Canada. Canadian Medical Association Journal, 170(11).

Bates, D. W. (2007). Preventing medication errors: A summary. American Journal of Health-System Pharmacy, 64(14 Suppl 9), S3-S9; quiz S24-S6. Erratum in: American Journal of Health-System Pharmacy.

Bates, D. W., Cullen, D. J., Laird, N., Petersen, L. A., Small, S. D., Servi, D., et al. (1995). Incidence of adverse drug events and potential adverse drug events: Implications for prevention. Journal of the American Medical Association, 274(1), 29-34.

Brennan, T. A., Leape, L. L., Laird, N. M., Hebert, L., Localio, A. R., Lawthers, A. G., et al. (1991). Incidence of adverse events and negligence in hospitalized patients. Results of the Harvard medical practice study I. New England Journal of Medicine, 324(6), 370-376.

Commonwealth Department of Health and Family Services. (1996). Final report of the Taskforce on Quality in Australian Healthcare, Australian Health Ministers' Advisory Council. Canberra, Australia: Australian Government Publishing Service.

Jolly, J. D., Hildebrand, E. A., Branaghan, R. J., Wu, Q., Garland, T., Epstein, D., et al. (2010). Patient safety and endoscope reprocessing: A usability test of the reprocessing procedure. Human Factors and Ergonomics in Manufacturing \& Service Industries. Submitted for publication.

Kohn, L. T., Corrigan, J. M., Donaldson, M. S. (Eds.). (2000). To err is human: Building a safer health system. Institute of Medicine, Committee on Quality of Health Care in America, National Academies Press, Washington, DC.

Lingard, L., Espin, S., Whyte, S., Regehr, G., Baker, G. R., Reznick, R., et al. (2004). Communication failures in the operating room: An observational classification of recurrent types and effects. Quality and Safety in Health Care, 13, 330e4.

Mogensen, T. S., Poulsen, J., Wendelboe, B., et al. (2002). Patient safety in Denmark - a year after the pilot study. Ugeskrif for Laeger, 164, 4377-4379.

Neily, J., Mills, P. D., Young-Xu, Y., Carney, B. T., West, P., Berger, D. H., et al. (In press). Association between 
implementation of a medical team training program and surgical mortality. Journal of the American Medical Association, 304(15), 1693-1700.

Schimmel, E. M. (2003). The hazards of hospitalization. Quality and Safety in Health Care, 12, 58-63. (This is a reprint of an article that appeared in Annals of Internal Medicine, 1964, Volume 60, pages 100110.)

Steel, K., Gertman, P. M., Crescenzi, C., \& Anderson, J. (2004). Iatrogenic illness on a general medical service at a university hospital. Quality and Safety in Health Care, 13, 76-80. (This is a reprint of an article that appeared in New England Journal of Medicine, 1981, Volume 304, pages 638-642.)

Sutcliffe, K. M., Lewton, E., \& Rosenthal, M. M. (2004). Communication failures: An insidious contributor to medical mishaps. Academic Medicine, 79, 186e94.

The Joint Commission National Patient Safety Goals. (2010). Retrieved September 17, 2010, from http://www.jointcommission.org/patientsafety/ nationalpatientsafetygoals

The Joint Commission's Annual Report on Quality and Safety. (2003). Improving America's Hospitals. Retrieved September 17, 2010, from http://www .jointcommission.org/NR/rdonlyres/658A9BB9-34854ACB-91BF-FCDCA73E4F30/0/2007_Annual_Report .pdf

VA National Center for Patient Safety Endoscope alerts: http://www.patientsafety.gov/alerts/ OlympusScopesAlertAL09-07-WWW.pdf (Retrieved September 17, 2010) http://www.patientsafety.gov/ alerts/FlexibleEndoscopeBiopsyValvesAL08-13.pdf

(Retrieved September 17, 2010) http://www .patientsafety.gov/alerts/SterisSystemIAlertAL08-11 .pdf (Retrieved September 17, 2010) http://www .patientsafety.gov/alerts/ResectoscopeWorking ElementReprocessing.pdf (Retrieved September 17, 2010) 